\title{
VARIAÇÕES TEXTURAIS INDUZIDAS PELO VENTO NOS SEDIMENTOS DA FACE DA PRAIA (PRAIA DE ATALAIA, PIAUÍ)
}

\author{
ABÍLIO CARLOS DA SILVA PINTO BITTENCOURT*, JOSÉ MARIA LANDIM DOMINGUEZ* \\ e ORDÔNIO MOITA FILHO**
}

\begin{abstract}
WIND-INDUCED TEXTURAL CHANGES OF THE BEACH FACE SEDIMENTS OF ATALAIA BEACH, PIAUI. Sediment textural changes on the beach face of the Atalaia beach (city of Luís Correia, Piauí) result of the interaction of two different processes: 1 . swash activity and 2. alternating dry and wet seasons. The last of these two processes was investigated in detail at lhe study area. During the dry season (August to December), onshore winds, with mean speads higher than $4.0 \mathrm{~m} / \mathrm{s}$, remove a significant portion of the fine to very fine sand size fraction of the beach face sediments, depositing it on the adjacent active dune fields. As a result, during this period beach face sands have high median values, averaging $0.700 \mathrm{~mm}$. During the wet season (January to April) the uninterrupted rains damp the sediments. This in association with milder onshore winds inhibit the removal of the fine sediment fractions from the beach face. Thus, beach sands during this period are mostly composed by fine to very fine sand (about $90 \%$ ) with mean values averaging $0.150 \mathrm{~mm}$. Preservation in the strati graphic record of these climatic-produced textural changes depends on rates of shoreline progradation. Best chances of preservation are associated with high progradation rates. This research also shows that, in the study area, sediment supply to the dune field is closelly related to seasonal changes in atmospheric precipitation which are ultimately controlled by latitudinal shifts of the Intertropical Convergence Zone (ITCZ). Thus, climatic changes impeding the southward movement of the ITCZ during summer-fall will result in a significant decrease of precipitation over the study area, therefore increasing sediment transport from the beach face to the dune field. This will translate into a major expansion of the dune field.
\end{abstract}

Keywords: Beach face lamination, dune fields, climatic changes.

\begin{abstract}
RESUMO Na praia de Atalaia (município de Luís Correia, Piauí), as variações nas características texturais do sedimento da face da praia resultam da interacão de dois processos diferentes: 1. a atividade do movimento de ressaca das ondas e 2. a alternância de estações secas e chuvosas. O último desses dois processos foi investigado em detalhe nessa praia. Durante a estação seca, de agosto a dezembro, os ventos que sopram continente adentro, com velocidades médias superiores a $4,0 \mathrm{~m} / \mathrm{s}$, removem da face da praia uma porção significativa das frações de areia fina a muito fina depositando-a no campo de dunas ativas contíguo. Como consequência, nesse período as areias da face da praia apresentam altos valores da mediana, em torno de $0,700 \mathrm{~mm}$. Durante a estação chuvosa, de janeiro a abril, as chuvas ininterruptas umedecem o sedimento praial. Este fato, associado a ventos que sopram continente adentro com velocidades mais baixas na estação chuvosa, inibe a remoção das frações finas do sedimento da face da praia. Desse modo, durante esse período o sedimento praial é composto principalmente por areias finas e muito finas (cerca de $90 \%$ ), com valores da mediana em torno de $0,150 \mathrm{~mm}$. A preservação no registro estratigráfico dessas variaç̃es texturais produzidas pelo clima depende da velocidade de progradação da linha de praia. As melhores chances de preservação estão associadas com altas velocidades de progradação. Este trabalho também mostra que, na área estudada, o suprimento de sedimentos para o campo de dunas está inteiramente relacionado às variações sazonais na precipitação atmosférica que são, em última análise, controladas por mudanças latitudinais da Zona de Convergência Intertropical (ZCIT). Assim, mudanças climáticas que impeçam o deslocamento para o sul da ZCIT durante o verão-outono resultarão em um significativo decréscimo da precipitação sobre a área estudada, aumentando, portanto, o transporte de sedimento da face da praia para o campo de dunas. Este fato se traduzirá em uma maior expansão do campo de dunas.
\end{abstract}

Palavras-chaves: Láminação da face da praia, campo de dunas, mudanças climáticas.

INTRODUÇÃO Os depósitos da face da praia superior, que se estendem da crista do berma à zona de saturação, onde o lençol freático aflora na superfície da praia, são constituídos caracteristicamente por uma laminação paralela a subparalela, mergulhando no sentido do mar com ângulos muito baixos (Thompson 1937, McKee 1957, Bigarella et al. 1966, Martins 1967). Observações realizadas por Clifton (1969) indicam que a unidade de sedimentação que caracteriza essa laminação apresenta caráter duplo. Dentro de cada uma dessas unidades uma lâmina basal de areia fina e/ou escura (minerais pesados) grada no sentido do topo para uma lâmina de areia grossa e/ou clara (minerais leves) (Fig. 1). Quanto à origem das laminações, Thompson (1937), Grant (1943) e McKee (1957) acreditam que esteja relacionada a variações no poder de transporte das ondas, à medida que novas lâminas só vão sendo adicionadas quando a deposição pelo movimento de saca de uma determinada onda excede a erosão causada pela ressaca da mesma onda. Segundo Clifton (1969), as laminações são produzidas na zona de lavagem pelo fluxo da ressaca. Este fluxo se caracteriza por uma densa nuvem de sedimentos em suspensão com espessura de $1-2 \mathrm{~cm}$. Processos de fluxo no interior desta camada em movimento, com partículas densamente concentradas, irão originar uma segregação de grãos grossos em direção ao topo e de mais finos para a base do fluxo, produzindo-se dessa maneira a unidade de sedimentação dupla mencionada anteriormente (Clifton 1969). Onde lâminas claras e escuras se alternam na praia, a unidade de sedimentação resultante desses processos de fluxo apresenta uma gradação mineralógica, sendo a camada basal caracterizada por uma concentração de minerais acessórios pesados, tais como magnetita e ilmenita. Sobre esta camada escura aparece uma concentração de minerais acessórios de densidade ligeiramente inferior, tais como anfibólios e piroxênios, que gradam para cima em areias quartzosas, refletindo para cima um decrés-

\footnotetext{
* Programa de Pesquisa e Pós-Graduação em Geofísica e Instituto de Geociência da UFBa, Rua Caetano Moura, 123, Campus Universitário da Federação, CEP 40000, Salvador, Bahia, Brasil

** Fundação Universidade Federal do Piaú, Departamento de Biologia, Centro de Ciências da Natureza, CEP 64000, Teresina, Piauí, Brasil
} 


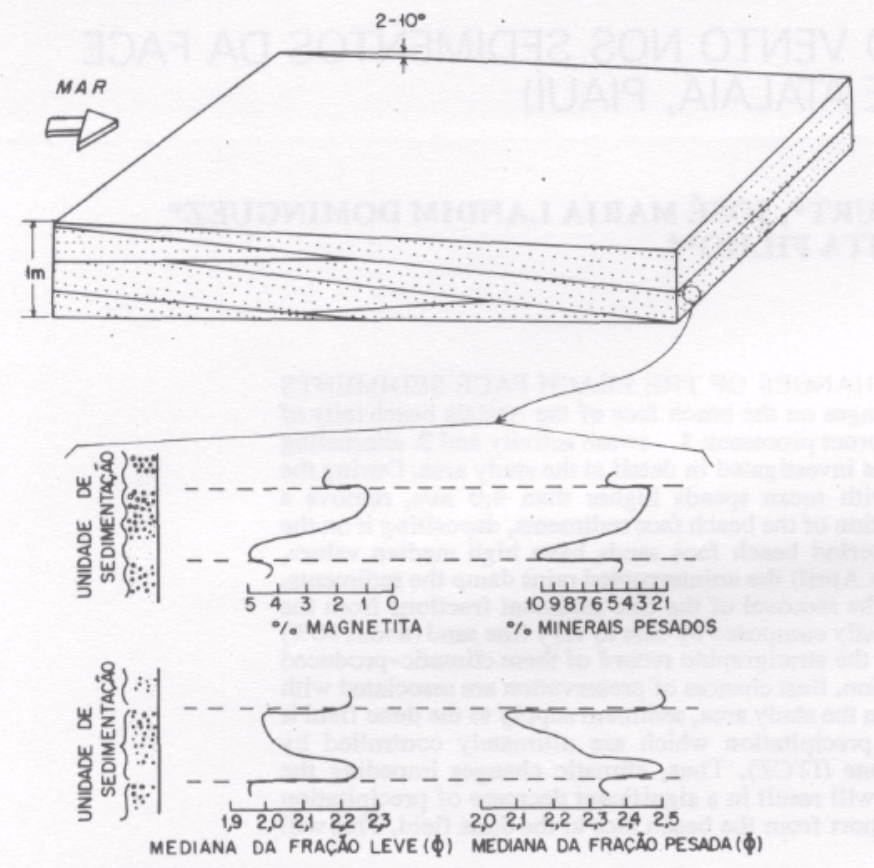

Figura 1 - Variações texturais e mineralógicas presentes nas laminações da face da praia (modificado de Clifton 1969)

Figure 1 - Textural and mineralogical variations characteristic of the beach face lamination (modified from Clifton 1969)

cimo por densidade na gradação (Clifton 1969).

Recentemente, foi realizado um trabalho na praia de Atalaia, no município de Luís Correia, Estado do Piauí (Fig. 2), visando definir os períodos de maior e menor movimentação de areia, sob a ação dos ventos, da praia para as dunas costeiras dessa região (Foto 1) bem como a repercussão dessa remoção de areia nas características granulométricas do sedimento praial. Como resultado, foram obtidos dados significativos que demonstram ser o vento, também, um agente efetivo na produção de variações texturais nos sedimentos da face da praia, as quais poderão vir a ser preservadas no registro geológico. Este mecanismo, que não tem sido considerado pela literatura clássica sobre o assunto, será o objeto de discussão do presente trabalho.

A costa do Estado do Piauí é caracterizada pela existência de extensos campos de dunas ativas, notadamente na região da foz do Rio Parnaíba e do rio Igaraçu, nos municípios de Parnaíba e Luís Correia (Fig. 2). São dunas do tipo barcana, que indicam um sentido predominante de ventos provindos de ENE (Foto 1), o que foi comprovado por Bigarella (1972) a partir de 145 medidas de estratificações cruzadas realizadas nas dunas da região de Luís Correia, que apresentaram uma direção média de mergulho para $\mathrm{S} 76 \mathrm{~W}$. A praia de Atalaia (Fig. 2) pode ser considerada como do tipo que Wright \& Short (1982) denominam de dissipativa, apresentando uma face da praia ampla e com baixa declividade, onde inexistem bermas, aliada à existência de uma grande abundância de areia na plataforma continental, que, segundo o Projeto REMAC (1979), tem aí cerca de $80 \mathrm{~km}$ de largura e uma baixa declividade. Praias desse tipo, segundo Short \& Hesp (1982), apresentam os mais baixos distúrbios no fluxo de areia pela ação do vento sendo assim, portanto, freqüentemente caracterizadas por grandes campos de dunas na planície costeira contígua. Na região de Luís Correia o campo de dunas tem uma largura máxima de $5 \mathrm{~km}$ (Foto 1 ).

O clima da região, segundo a classificação de Köppen, é do tipo $\mathrm{A} \mathrm{w}^{\prime}$, quente e úmido, com chuvas de verão-outono

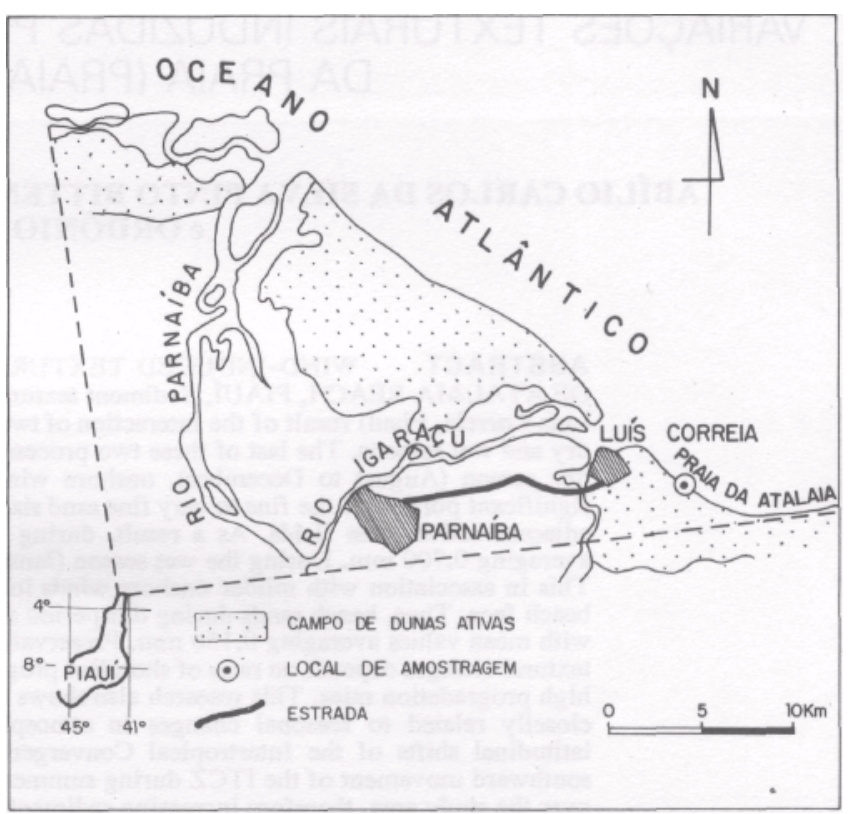

Figura 2 - Mapa de localização da praia de Atalaia mostrando o posicionamento do local de amostragem

Figure 2 - Location map of the Atalaia beach showing sampling site

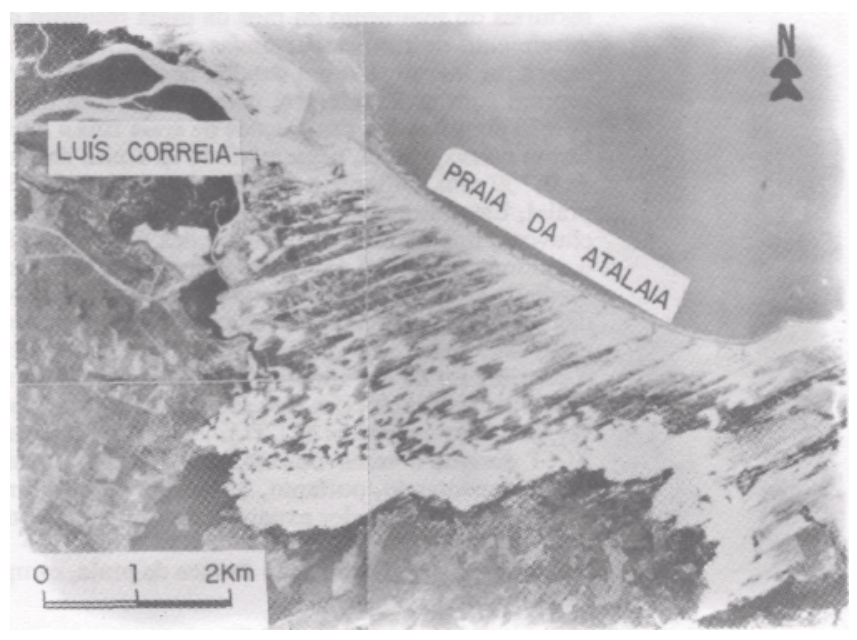

Foto 1 - Campo de dunas ativas, do tipo barcana, contíguo à praia de Atalaia (Luís Correia, Piauí)

Photo 1 - Active dune field (barchan dunes) landward of the Atalaia beach (Luís Correia, Piauí)

resultantes dos deslocamentos sazonais da Zona de Convergência Intertropical (ZCIT) ao longo da costa, alcançando uma pluviosidade de 1.000 a $1.250 \mathrm{~mm}$ anuais (Lins 1978). Segundo Rebouças \& Marinho (1972), o restante do ano fica praticamente sem chuvas. Os ventos alísios de NE e E predominam durante todo o ano, o que pode ser constatado pelo exame da figura 3. Durante o período de observações do presente trabalho, segundo dados colhidos no Posto de Meteorologia da cidade de Parnaíba, localizada a cerca de $10 \mathrm{~km}$ da região estudada, a velocidade dos ventos variou de 2,1 a $5,9 \mathrm{~m} / \mathrm{s}$. As marés na região de Luís Correia são semidiurnas, alcançando um máximo de 3,5 m (Diretoria de Hidrografia e Navegação 1988). Observações realizadas 
durante o período de monitoramento do presente trabalho mostram que as ondas, em sua quase totalidade provindas de .ENE, apresentaram sempre pequenas alturas, entre 0,50 e $0,75 \mathrm{~m}$, alcançando o litoral com ângulos de $15^{\circ}$ a $20^{\circ}$ (observação visual). Essas ondas quebram sempre distantes da praia e, quando alcançam a mesma, já estão bastante dissipadas.

Para a realização do presente trabalho foram monitoradas as variações texturais do sedimento praial ao longo de nove meses consecutivos, de agosto de 1985 a abril de 1986, mediante a análise de 21 amostras coletadas no período. As amostras, representativas das primeiras lâminas de areia da superfície, com até $2 \mathrm{~cm}$ de profundidade, foram sempre colhidas em um mesmo ponto (Fig. 2), situado na parte mediana da face da praia, e sempre o máximo possível próximo ao horário da baixa-mar. De cada amostra, secada e quarteada, foi retirada uma quantidade em torno de $50 \mathrm{~g}$, da qual se eliminaram os sais solúveis. Após esse tratamento, a amostra foi peneirada a. seco com Rotap, através de um conjunto de peneiras com intervalo de $1 / 20$.

VARIAÇÕES NOS REGIMES DE VENTOS E DE
CHUVAS NA REGIÃO DE LUÍS COR\&EIA DURANTE O PERÍODO DE AGOSTO DE 1985 A ABRIL DE 1986

A figura 3 mostra os dados colhidos no Posto de Meteorologia da cidade de Parnaíba, que, como já se sabe, fica bem próxima de Luís Correia, podendo assim esses dados serem considerados como válidos para a última cidade. Pelo exame da figura 3 observa-se que houve, durante todo o período de observações, uma predominância marcante de ventos

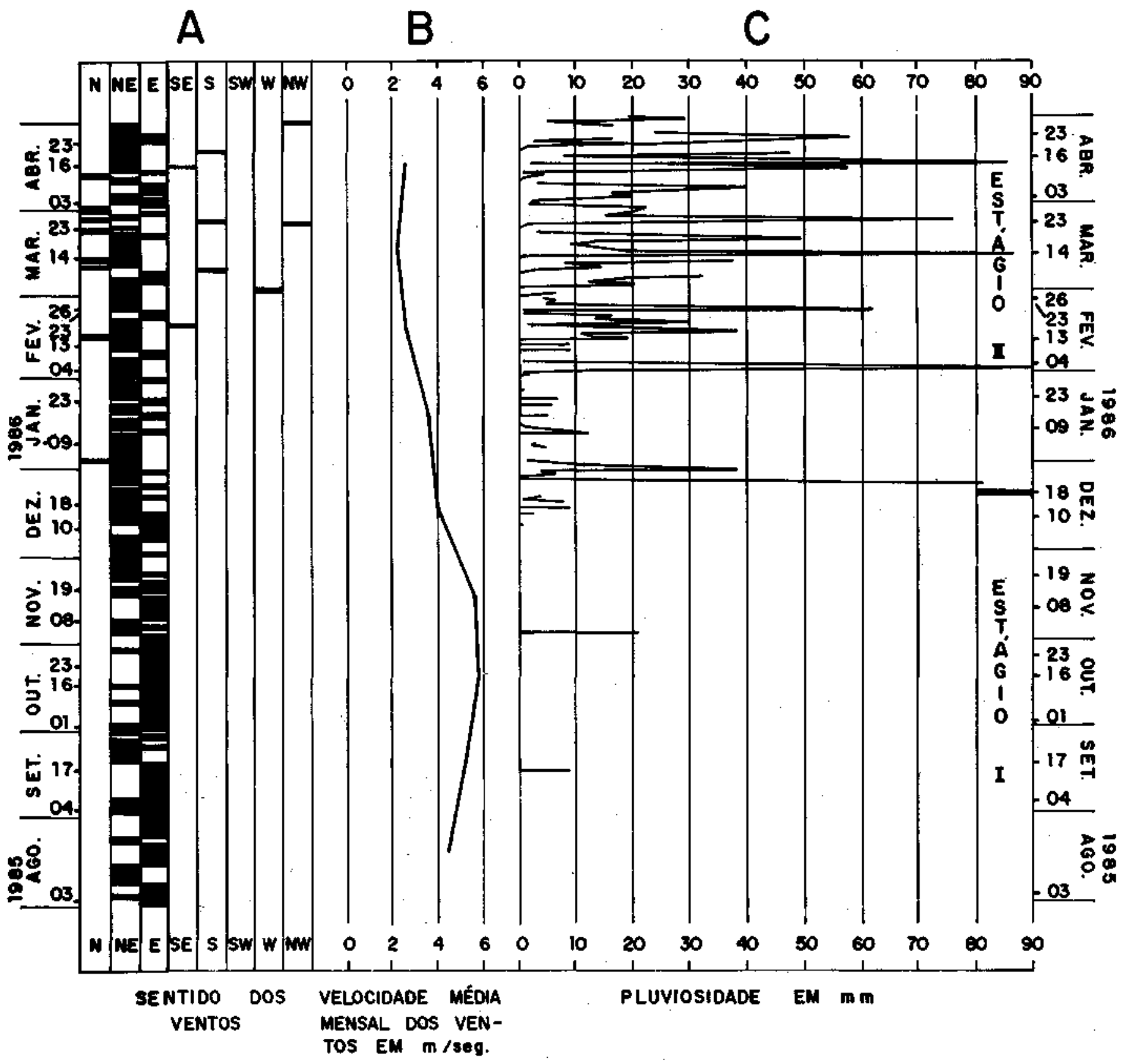

Figura 3 - Condições meteorológicas na região de Luís Correia durante o período de agosto de 1985 a abril de 1986. O gráfico aponta ainda os dias das coletas de amostras na praia bem como os dois estágios em que o mesmo foi dividido, segundo critérios mencionados no texto

Figure 3 - Meteorological conditions at the Luis Correia region for the period August 19857April 1986. The graph also shows: 1. days of sampling collection, and 2. lhe two stages of temporal textura! variations documented for the beach fine at the Atalaia beach. See text for details 
provindos de E e NE, sendo que, no período de agosto a dezembro de 1985, eles são os únicos existentes. Nos demais meses aparecem, esporadicamente, ventos provenientes de outros quadrantes.

Quanto à velocidade dos ventos, em termos de valores médios mensais, a figura 3 mostra que os mesmos, de agosto a dezembro de 1985, foram sempre superiores a $4,0 \mathrm{~m} / \mathrm{s}$, atingindo um máximo de $5,9 \mathrm{~m} / \mathrm{s}$ em outubro. De dezembro de 1985 a abril de 1986 as velocidades foram menores, sempre inferiores a 4,0 m/s. Como recomenda o Manual de Proteção da Costa (Shore Protection Manual, CERC 1984), as velocidades de ventos medidas em estações terrestres devem ser corrigidas quando extrapoladas para situações de mar aberto. Assim, utilizando-se as curvas publicadas naquele manual, as velocidades de ventos medidas na cidade de Parnaíba devem ser multiplicadas por um fator entre 1,4 e 1,5 antes de serem extrapoladas para a área estudada. Assim é que as velocidades de 5,9 e $4,0 \mathrm{~m} / \mathrm{s}$ reportadas acima para a cidade de Parnaíba devem ser corrigidas para 8,2 e $6,0 \mathrm{~m} / \mathrm{s}$, respectivamente, antes de extrapoladas para a área estudada.

Em relação à pluviosidade, constata-se uma faixa de tempo em que praticamente não choveu, de agosto a dezembro de 1985 (Fig. 3), tendo sido o restante do período de observação, na maioria do tempo, contrariamente, caracterizado por chuvas fortes e continuadas (Fig. 3).

VARIAÇÕES NO TEMPO NAS CARACTERÍSTICAS TEXTURAIS DO SEDIMENTO PRAIAL A figura 4 mostra as variações ocorridas na granulometria do sedimento praíal ao longo do período de monitoramento. O gráfico pode ser dividido em dois estágios, I e II, que apresentam características granulométricas bem distintas. O limite entre esses estágios não tem uma posição perfeitamente definida, podendo no entanto ser fixado dentro de uma estreita faixa de tempo. O posicionamento do mesmo no local em que aparece na figura 4 foi feito devido ao fato de ele aí marcar importantes mudanças nas características climáticas (Fig. 3), que, como se verá, são refletidas nas variações texturais do sedimento praial. O estágio I é caracterizado por ser constituído, em sua grande maioria, de uma mistura predominante de areias média, grossa e muito grossa. O estágio II, diferentemente, apresenta uma predominância de uma mistura de areias fina a muito fina, que, no mais das vezes, correspondem a mais de $90 \%$ da composição granulométrica.

A figura 5 mostra as variações nos valores da mediana ocorridos durante o período de observação. É bem ressaltado o fato de a mediana apresentar os maiores valores no estágio I, atingindo máximos em torno de $0,700 \mathrm{~mm}$, com muito pouca variação.

DISCUSSÃO O mais notável nos gráficos das variações temporais nas características granulométricas analisadas é a divisão dos mesmos em dois estágios, bem marcados, com aspectos bem distintos (Figs. 4 e 5). Esses estágios, com o limite entre ambos posicionando-se coincidentemente nesses gráficos, podem também ser perfeitamente identificados no gráfico que mostra as variações climáticas na região durante o período de monitoramento (Fig. 3). Assim, observa-se que o estágio I é caracterizado por uma faixa de tempo em que a pluviosidade foi praticamente nula (Fig. 3), bem como por apresentar velocidades do vento sempre superiores a $4,0 \mathrm{~m} / \mathrm{s}$ (valores não corrigidos) (Fig. 3). Do ponto de vista textural, o estágio I é caracterizado por apresentar uma composição granulométrica predominante de areias média, grossa e muito grossa (Fig. 4) e altos, valores da mediana (Fig. 5). O estágio II porém, corresponde a uma faixa de tempo em que a pluviosidade foi alta, chovendo de uma maneira quase ininterrupta no período monitorado (Fig. 3). Além disso, as velocidades dos ventos foram sempre mais baixas que no estágio I (Fig. 3). Texturalmente, o sedimento praial, durante o estágio II, caracteriza-se por
PERCENTAGEM

ESTAGIOS

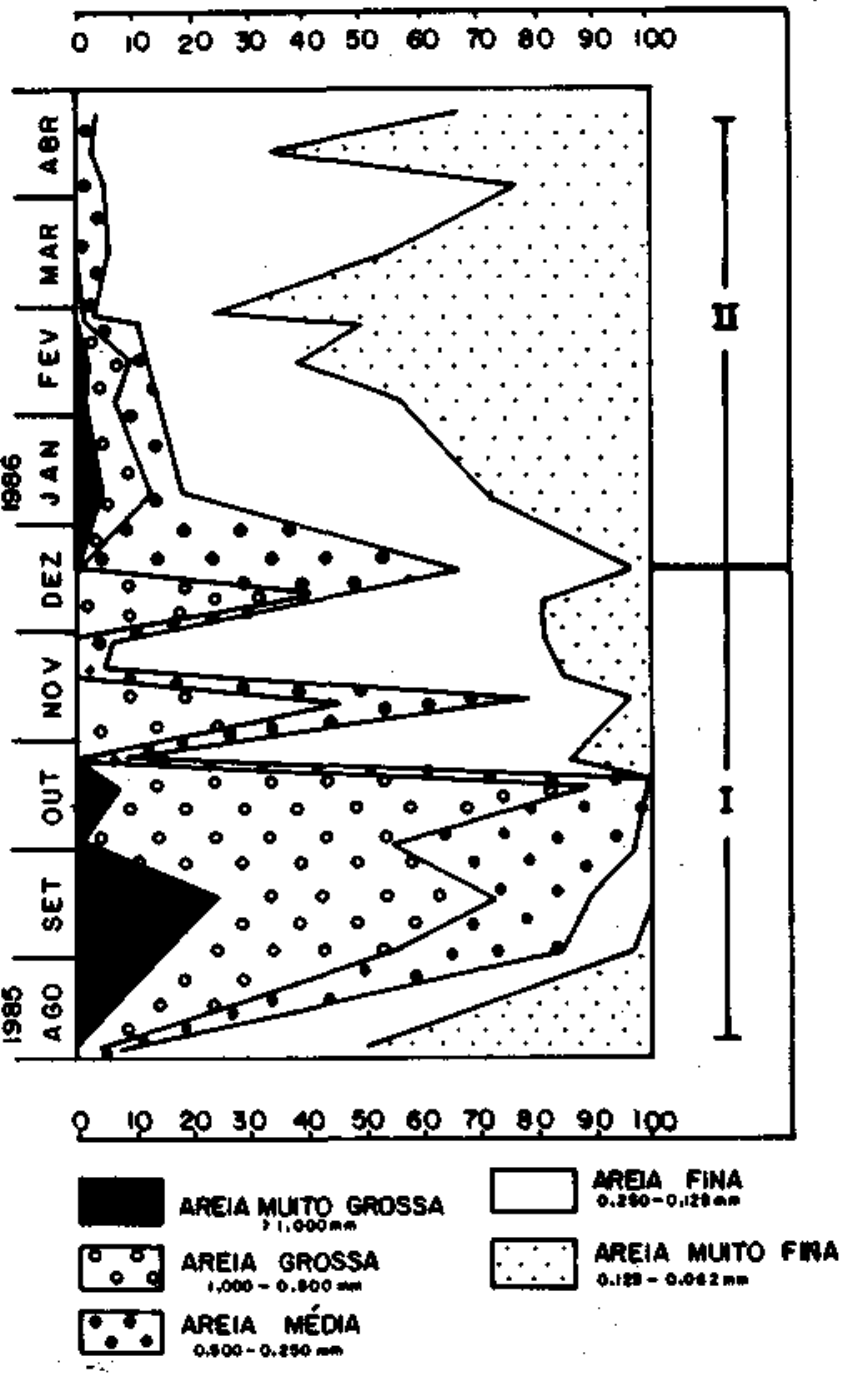

Figura 4 - Variações na composição granulométrica do sedimento praial ao longo do tempo

Figure 4 - Temporal textural variations documented for the beach face at the Atalaia beach

apresentar uma composição predominante de areias fina a muito fina (Fig. 4) e valores da mediana baixos e com pouca variação (Fig. 5). A coincidência entre o limite do estágio I com o II nos gráficos representativos das características granulométricas do sedimento praial (Figs. 4 e 5) e o limite entre os mesmos estágios no gráfico que mostra as características climáticas da região (Fig. 3) durante o período de monitoramento sugere haver uma estreita relação entre ambas.

$\mathrm{O}$ fato de, durante todo o período de observações, as pequenas ondas ao alcançarem a face da praia já estarem com sua energia bastante atenuada permite considerar que as mesmas têm características construtivas, sendo pouco provável, portanto, que possam vir a exercer um papel ponderável na erosão da face da praia. Esse aspecto - aliado à existência de um vasto campo de dunas ativas contíguo à praia, atestando que os ventos soprados continente adentro têm competência suficiente para mover algumas frações granulométricas do sedimento praial - permite concluir que as características granulométricas dos estágios I e II estejam basicamente relacionadas com a ação dos ventos sobre a face da praia (Fig. 6). 


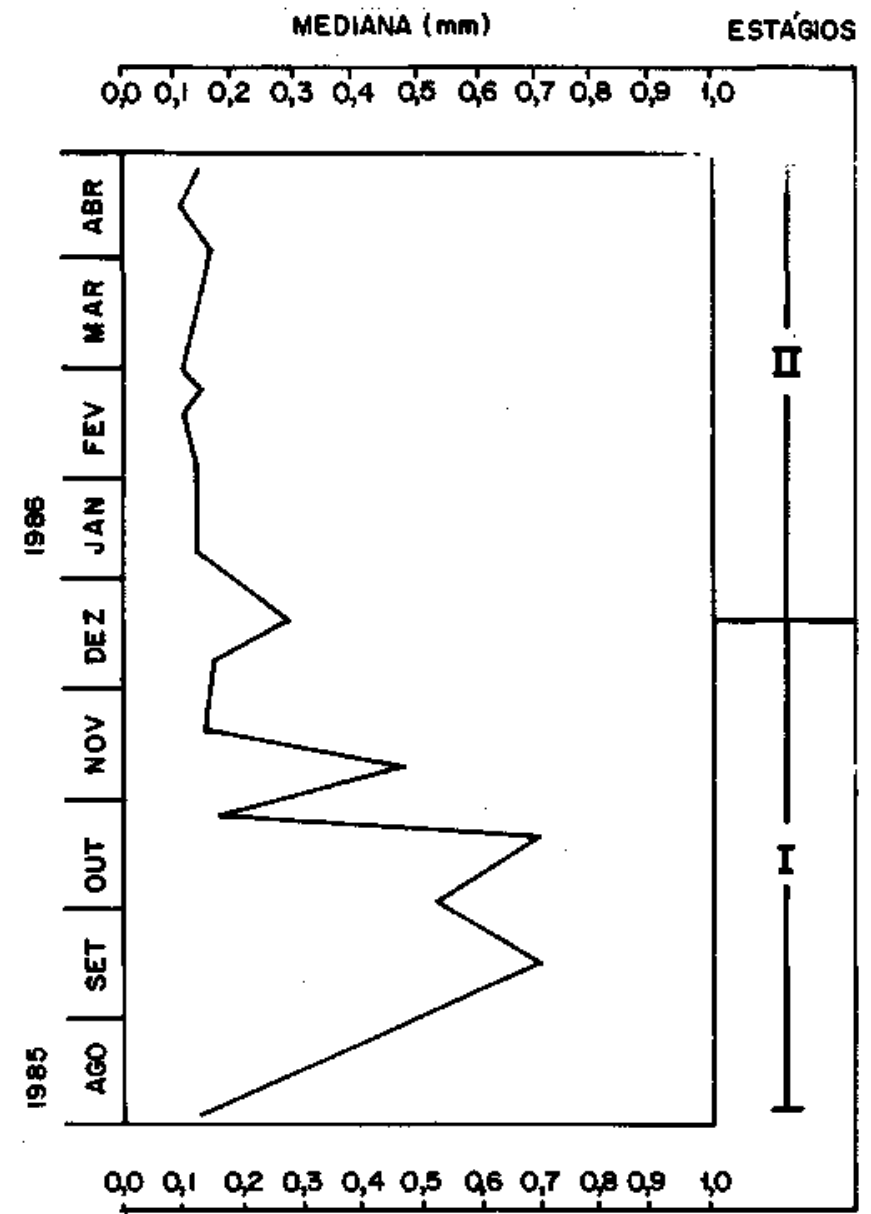

\section{Figura 5 - Variações nos valores da mediana ao longo do tempo}

Figure 5 - Temporal variations in median values of beach face sediments, for the Atalaia beach

Assim, durante o estágio I, quando os ventos apresentam as maiores velocidades e as chuvas são praticamente inexistentes (Figs. 3), as condições são ideais para a remoção de areia da face da praia para a planície costeira. Os sedimentos que continuamente estão-se incorporando à face da praia pela ação das ondas, mediante a migração de barras provindas da antepraia, devem ter uma composição granulométrica semelhante à apresentada pela praia no estágio II, mais especificamente de fevereiro de $1986 \mathrm{em}$ diante (Fig. 4), quando, como se verá, cessa praticamente a remoção de sedimentos finos na face da praia pela ação dos ventos, devendo refletir a mesma, portanto, a composição do material provindo da antepraia. Esses sedimentos, constituídos de mais de $90 \%$ de areias fina e muito fina, começam, a partir do início do período seco, em agosto de 1985 (Fig. 3), a sofrer a ação dos ventos alísios de E e NE (Fig. 3).

Desse modo, esses ventos, que apresentam velocidades (Fig. 3) consideradas por Garner (1974) e Pethick (1984) como competentes o suficiente para remover f rações arenosas finas de um sedimento praial, passam a retirar da praia de Atalaia as frações de areias fina e muito fina, transportando-as para a planície costeira e concentrando, como conseqüência, as frações mais grossas na face da praia (Fig. 4 e 6 A), com o que aumenta o valor da mediana (Fig. 6).

Durante o estágio II (Fig. 6B), os ventos, apesar de apresentarem velocidades inferiores às do I (Fig. 3), ainda têm

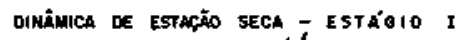
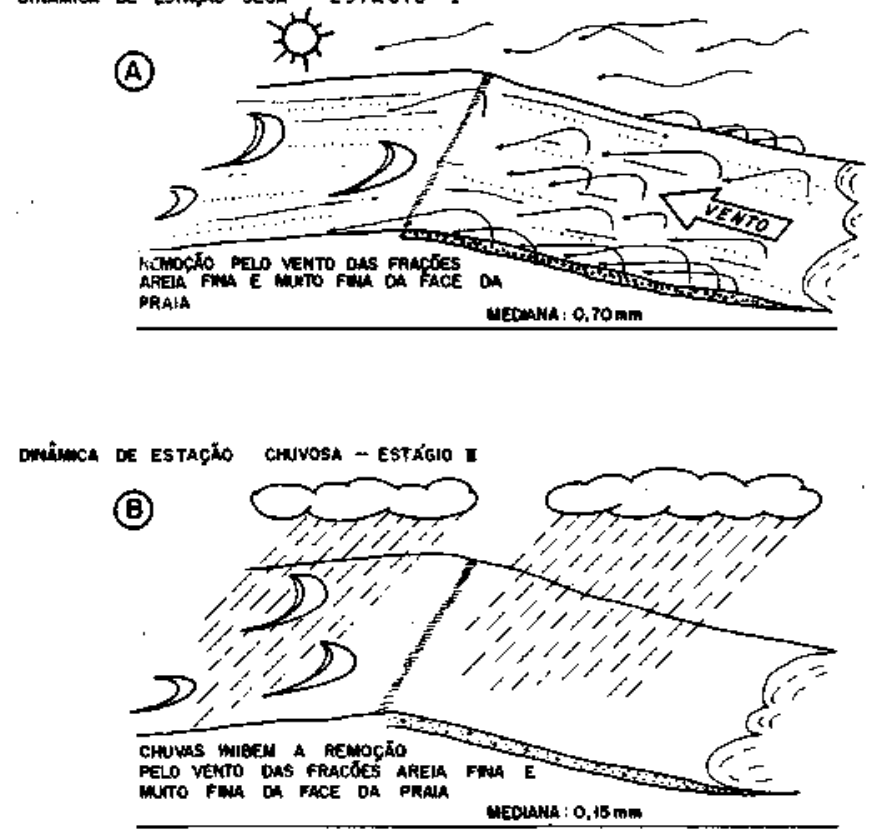

Figura 6-Modelo esquemâtico mostrando a origem das variações texturais observadas em sedimentos da face da praia na localidade de Atalaia (Luís Correia, Piauí)

Figure 6 - Scheme showing model for textural variations documented for the beach face of the Atalaia beach (Luis Correia, Piauí)

competência suficiente, segundo dados de Twenhofell (1950), para remover a fração de areia muito fina da praia. Essa remoção, todavia, não se dá nesse estágio devido à existência de chuvas durante todo o período (Fig. 3), fato que inibe a retirada de areia. Isso, que demonstra principalmente a importância da presença da umidade provocada pela ação das chuvas na areia da face da praia, em termos de a mesma dificultar a deflação de areia, por fazer aumentar consideravelmente as velocidades limiares (threshold velocities), já é bem conhecido na literatura, como pode ser visto em Bagnold (1941), Bigarella (1972), Davies (1977) e Freyberg et al. (1988). Desse modo, nesse estágio, sob a ação das ondas construtivas que estão trazendo continuamente materiais finos para a face da praia, o sedimento praial volta a apresentar uma composição granulométrica semelhante à do início do estágio I, basicamente constituída de areias fina a muito fina (Fig. 4) e, conseqüentemente, com valores baixos da mediana (Fig. 5). Apenas no início do estágio, quando as chuvas ainda não são muito concentradas (Fig. 3), o vento atua um pouco na face da praia removendo finos, aparecendo ainda, portanto, porcentagens de frações grossas um pouco superiores a $10 \%$ (Fig. 4), o que vai contudo gradativãmente diminuindo até valores inferiores a $5 \%$, à medida que as chuvas vão-se tornando intensas (Figs. 3 e 4).

CONCLUSÕES O presente trabalho descreveu um exemplo de variações texturais produzidas por ritmos climáticos, neste caso relacionado à alternância de estações seca e chuvosa. A preservação desse tipo de ritmo climático no registro geológico, entretanto, será complexa e está relacionada à magnitude das taxas de progradação da linha de costa (Fig. 7). Na área estudada, dois fenômenos são responsáveis pela produção de variações texturais na face da praia: 1. alternância de estações secas e chuvosas, descrita anteriormente, e 2 . o processo de saca e ressaca descrito em Clifton (1969). Esses fenômenos atuam em freqüências 

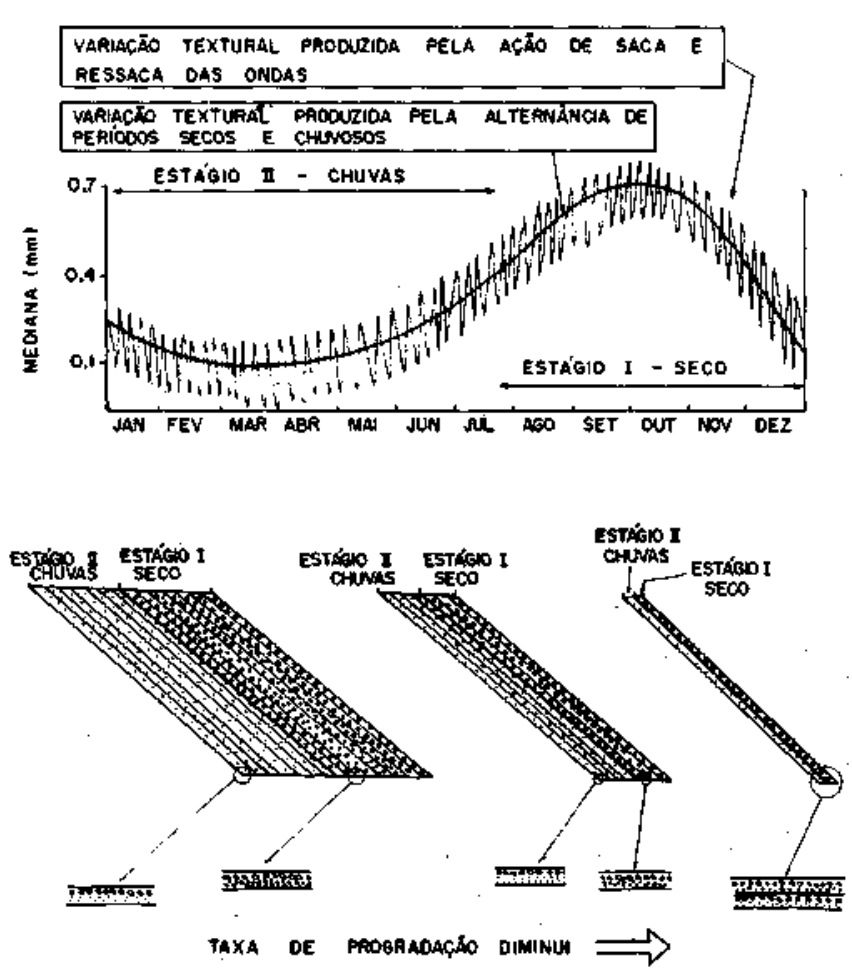

Figura 7-Modelo esquemático mostrando a influência da taxa de progradação na preservação de variações texturais em sedimentos da face da praia devidos à superimposição de $\mathbf{1}$. alternância de estações secas e chuvosas e 2. processo de saca e ressaca (ver texto para detalhes)

Figure 7 - Schematic model showing the influence of rates of progradation in the preservation of textura! variations documented for the beach face sediments. These variations result from superimposition of two phenomena: 1. alternating dry and rainy seasons and 2. wave swashbackwash. Activity on the veach (see text for details)

diferentes: da ordem de meses (baixa freqüência), para o primeiro fenômeno, e da ordem de segundos (alta freqüência), para o último (Fig. 7). Esses fenômenos ocorrem superimpostos e atuam simultaneamente. Assim é que, sob condições de elevadas taxas de progradação, duas camadas razoavelmente espessas, com características texturais contrastantes, serão formadas (Fig. 7). Internamente, cada uma dessas camadas exibirá laminações produzidas pelos processos de fluxo relacionados ao movimento de ressaca. À medida que as taxas de progradação decrescem, a preservação do registro de baixa frequência (alternância de estações seca e chuvosa) diminui (Fig. 7), até que em uma situação extrema de reduzida ou nenhuma progradação o registro sedimentar do ritmo climático (baixa freqüência) coincidirá com o registro sedimentar do movimento de ressaca (alta freqüência).

Os resultados obtidos neste trabalho oferecem ainda importantes subsídios para a compreensão da gênese dos campos de dunas que ocorrem nas regiões costeiras dos Estados do Maranhão e Piauí e de suas implicações paleoclimáticas.

A inspeção de fotos aéreas nas vizinhanças da área estudada mostra que o avanço das dunas costa adentro não foi um processo contínuo durante o Holoceno, mas ocorrem na forma de pulsos, separados por períodos em que a atividade eólica foi interrompida. Desse modo, diversas gerações de dunas podem ser cartografadas. Tal fenômeno não é exclusivo das regiões costeiras dos Estados do Maranhão e Piauí, tendo sido reportado para o litoral norte de Salvador (BA) (Martin et al. 1980) e para a zona de progradação do Rio São Francisco (Bittencourt et al. 1982).

Como a fonte de sedimentos que alimenta as dunas costeiras é a própria face da praia, fenômenos que interfiram com esse fornecimento irão, em última instância, afetar o desenvolvimento dos campos de dunas associados. Assim é que, na área estudada, o suprimento de sedimentos para os campos de dunas ocorre principalmente durante a estação seca, sendo interrompido na estação chuvosa. Esta estação chuvosa está associada diretamente ao deslocamento para sul, durante o verão-outono, da Zona de Convergência Intertropical. É possível, então, que mudanças climáticas afetando a posição da Zona de Convergência Intertropical e impedindo seu deslocamento para sul durante o verão-outono, possam resultar em diminuição acentuada da precipitação favorecendo dessa forma o desenvolvimento dos campos de dunas. Esses períodos corresponderiam aos pulsos de avanços das dunas costa adentro, referidas acima. Portanto, a documentação detalhada e a datação desses pulsos de avanço das dunas, dando origem às diferentes gerações de dunas observadas em fotografias aéreas, contribuirão de forma significativa para a reconstrução de mudanças climáticas e, em particular, no posicionamento da Zona de Convergência Intertropical durante o Holoceno.

Agradecimentos Os autores expressam seus agradecimentos ao $\mathrm{CNPq}$, pelo provimento dos recursos para a realização da pesquisa (Proc. 40.7121/84), e ao Prof. Olivar Antônio Lima de Lima, pelas críticas e sugestões apresentadas.

\section{REFERÊNCIAS BIBLIOGRÁFICAS}

BAGNOLD, R.A. 1941. The physics of blown sand and desert dunes. London, Chapmann \& Hall. 265 p.

BIGARELLA, JJ.; FREIRE, S.F.; S ALAMUNI, R.; VIANA, R. 1966. Contribuição ao estudo dos sedimentos praiais recentes. II-Praias de Marinho e Caiobá. Boi. Univ. Fed. Paraná - Geografia Física, 6:109 p.

BIGARELLA, J J. 1972. Eolian environments, their characteristics, recognition, and importance. In: RIGBY, J.K. \& HAMBLIN, $\mathrm{Wm}$. K. eds. Recognition of ancient sedimentary environments. SEPM. $n^{\circ}-16$, p. 12-62. (Special Publication).

BITTENCOURT, A.C.S.P.; DOMINGUEZ, J.M.L.; MARTIN, L.; FERREIRA, Y.A. 1982. Dados preliminares sobre a evolução do delta do rio São Francisco (SE/AL) durante o Quaternário: influência das variações do nível do mar. In: SIMPÓSIO IX) QUATERNÁRIO NO BRASIL, 4,1982,Aftw... p. 49-68.
COASTAL ENGINEERING RESEARCH CENTER - CERC 1984. Shore Protection Manual. U.S. Army Coastal Engineering Research Center. (W/o number).

CLIFTON, H.E. 1969. Beach lamination: nature and origin. Mar.Geol., 7:553-559.

DA VIES, J.L. 1977. Geographical variation in costal development. In: CLAYTON, K.M. ed. Geomorphology texts, $\mathrm{n}^{\mathrm{s}} 4$. Norfolk, England, Lowe \& Brydone Printers Ltd. 204 p.

DIRETORIA DE HIDROGRAFIA E NAVEGAÇÃO. 1988. Tábuas das marés para o ano de l'988 costa do Brasil e portos estrangeiros. Ministério da Marinha. $22 \mathrm{p}$.

FREYBERG, S.G.; SCHENK, C.J.; KRYSTINIK, L.F. 1988. Stokes surface and the effects of near-surface growndwter-table on eolian deposition. Sed., 35:21-41.

GARNER, H.F. 1974. The origin of landscapes - A study of 
geomorphology. London, Oxford University Press, Inc. 734 p.

GRANT, U.S. 1943. Waves as a sand-transporting agent. AmeJourJSd., 241:117-123.

LINS, R.C. 1978. Bacia do Parnalba: aspectos fisiográficos. Recife, Instituto Joaquim Nabuco de Pesquisas Sociais. 65 p.

MARTIN, L.; VILAS BOAS, C.S.; BITTENCOURT, A.C.S.P.

FLEXOR, J.M. 1980. Origine dês sables et ages dês dunes de Ia region de Salvador (Brésil). Consequences paleoclimatiques. CahierORSTOM, Ser. Géol., XI:125-132.

MARTINS, L.R. 1967. Aspectos texturais e deposicionais dos sedimentos praiais e eólicos da planície costeira do Rio Grande do Sul. Gráfica da Universidade Federal do Rio Grande do Sul. n-13, 102 p. (Publicação Especial).

McKEE, E.D. 1957. Primary structures in some recent sediments. BuUAmerAssocfet.Geol., 41:1704-1747.

PETHICK, J. 1984. An introduction to coastal geomorphology. London, Edward Arnold Ltd. $260 \mathrm{p}$

PROJETO REMAC 1979. Brasil, Margem Continental Norte - Mapa Batimétríco Esc. 1:3500.000. Rio de Janeiro, Pettobrás/CENPES/DINTEP.
REBOUÇAS, A. C. \& MARINHO, M.E. 1972. Hidrologia das secas Nordeste do Brasil. Sudene, $\mathrm{n}^{9} 41,126$ p. (Série Hidrogeologia). SHORT, A.D. \& HESP, P.A. 1982. Wave, beach and dune interactions in southeastern Australia. Mar. deal., 48:259-284.

THOMPSON, W.O. 1937. Original structures of beaches, bars, and dunes. Butt. Geol. Soc. Amer.. 48:723-725.

TWENHOFEL, W.H. 1950. Principles of sedimentation. New York, MacGraw-Hill.673p

WRIGHT, LD. \& SHORT, A.D. 1984. Morphodynamic variability of surf zones and beaches: a Synthesis. Mar. Geol., 56:93-118.

MANUSCRITO A618

Recebido em 18 de agosto de 1989 Revisão do Autor em 16 de novembro de 1989 Revisão aceita em 16 de novembro de 1989 